Research Paper

\title{
Downregulation of lipin-1 induces insulin resistance by increasing intracellular ceramide accumulation in $\mathrm{C} 2 \mathrm{C} 12$ myotubes
}

\author{
Shujuan Huang 1,2, Suling Huang ${ }^{1}$, Xi Wang 1, Qingli Zhang ${ }^{3}$, Jia Liu ${ }^{3}$, Ying Leng 1, ${ }^{凶}$ \\ 1. State Key Laboratory of Drug Research, Shanghai Institute of Materia Medica, Chinese Academy of Sciences, Zu Chong Zhi Road 555, Shanghai 201203, \\ China. \\ 2. University of Chinese Academy of Sciences, No.19A Yuquan Road, Beijing 100049, China. \\ 3. Shanghai Institute of Materia Medica, Chinese Academy of Sciences, Zu Chong Zhi Road 555, Shanghai 201203, China. \\ $\square$ Corresponding author: State Key Laboratory of Drug Research, Shanghai Institute of Materia Medica, Chinese Academy of Sciences, 555 Zuchongzhi Road, \\ Shanghai, 201203, PR China. Email address: yleng@simm.ac.cn (Y. Leng). \\ (C) Ivyspring International Publisher. This is an open access article distributed under the terms of the Creative Commons Attribution (CC BY-NC) license \\ (https://creativecommons.org/licenses/by-nc/4.0/). See http://ivyspring.com/terms for full terms and conditions.
}

Received: 2016.08.09; Accepted: 2016.09.30; Published: 2017.01.01

\begin{abstract}
Dysregulation of lipid metabolism in skeletal muscle is involved in the development of insulin resistance. Mutations in lipin-1, a key lipid metabolism regulator leads to significant systemic insulin resistance in fld mice. However, the function of lipin-1 on lipid metabolism and insulin sensitivity in skeletal muscle is still unclear. Herein we demonstrated that downregulation of lipin-1 in $\mathrm{C} 2 \mathrm{Cl} 2$ myotubes by siRNA transfection suppressed insulin action, characterized by reduced insulin stimulated Akt phosphorylation and glucose uptake. Correspondingly, decreased lipin-1 expression was observed in palmitate-induced insulin resistance in $\mathrm{C} 2 \mathrm{C} 12$ myotubes, suggested that lipin-1 might play a role in the etiology of insulin resistance in skeletal muscle. The insulin resistance induced by lipin-1 downregulation was related to the disturbance of lipid homeostasis. Lipin-1 silencing reduced intracellular DAG and TAG levels, but elevated ceramide accumulation in $\mathrm{C} 2 \mathrm{C} 12$ myotubes. Moreover, the impaired insulin stimulated Akt phosphorylation and glucose uptake caused by lipin-1 silencing could be blocked by the pretreatment with SPT inhibitor myriocin, ceramide synthase inhibitor FB1, or PP2A inhibitor okadaic acid, suggested that the increased ceramide accumulation might be responsible for the development of insulin resistance induced by lipin-1 silencing in $\mathrm{C} 2 \mathrm{Cl} 2$ myotubes. Meanwhile, decreased lipin-1 expression also impaired mitochondrial function in $\mathrm{C} 2 \mathrm{C} 12$ myotubes. Therefore, our study suggests that lipin-1 plays an important role in lipid metabolism and downregulation of lipin-1 induces insulin resistance by increasing intracellular ceramide accumulation in $\mathrm{C} 2 \mathrm{Cl} 2$ myotubes. These results offer a molecular insight into the role of lipin-1 in the development of insulin resistance in skeletal muscle.
\end{abstract}

Key words: lipin-1; skeletal muscle; insulin resistance; lipid metabolism; ceramide.

\section{Introduction}

Type 2 diabetes mellitus (T2DM) is a complex metabolic disorder that is characterized by abnormal glucose and lipid metabolism due to insulin resistance and impaired insulin secretion [1]. The insulin resistance in skeletal muscle is a major determinant of hyperglycaemia and T2DM, since it is the major site for glucose metabolism, and account for approximately $80 \%$ of whole body glucose disposal under insulin-stimulated conditions in the postprandial state $[2,3]$. Moreover, skeletal muscle insulin resistance is evident decades before $\beta$-cell failure and is considered as the primary defect of type 2 diabetes $[4,5]$. Hence, exploring the mechanisms of insulin resistance in skeletal muscle is important and will offer clues to the discovery of the new strategy for type 2 diabetes treatment.

Intramyocellular lipid intermediates accumulation is strongly linked to the development of insulin 
resistance in skeletal muscle. Lipid intermediates such as ceramide, diacylglycerol (DAG) or long-chain acyl-CoA all have the potential to reduce skeletal muscle insulin sensitivity [6-8]. Among these lipid species, ceramide is considered as the most active lipid intermediates to blunt insulin action [9]. Strong positive relationship between ceramide accumulation and insulin resistance of skeletal muscle is found in diabetes animal models and human subjects [10-12]. In $\mathrm{C} 2 \mathrm{C} 12$ mytobues, ceramide directly stimulates protein phosphatase 2A (PP2A), a ubiquitously expressed cytoplasmic serine/threonine phosphatase to promote PKB/Akt dephosphorylation [13]. Furthermore, defective control of lipid metabolism in skeletal muscle, such as impaired triacylglycerides (TAG) synthesis or mitochondrial metabolism may channel fatty acids (FAs) into ceramide generation and inhibit insulin signal transduction [14, 15].

Lipin-1 was identified as the gene mutated in the fatty liver dystrophy (fld) mouse and is highly expressed in metabolically active tissues such as adipose tissue and skeletal muscle [16]. Recently, lipin-1 is emerging as a key regulator in lipid metabolism at multiple nodal points. Lipin-1 functions as phosphatidate phosphatase (PAP) enzyme which catalyzes the dephosphorylation of phosphatidic acid (PA) to DAG, the penultimate step of TAG synthesis [17]. In addition, lipin-1 can translocate to nucleus and acts as a transcriptional regulator to inhibit or enhance genes expression involved in lipid metabolism [18, 19]. Fld mice exhibits profound glucose intolerance, hyperinsulinmia and insulin resistance, which is speculated to due to the impaired differentiation of adipose tissue [20]. To date, the physiological function of lipin- 1 in adipose tissue has been well studied [19, 21, 22]. Nevertheless, the function of lipin-1 in skeletal muscle is remaining unclear. Result from the muscle-specific lipin-1 transgenic mice shows that lipin-1 expression enhancement reduces energy expenditure and systemic insulin sensitivity [23]. Contradict with this result, lipin-1 expression increases after exercise and AMPK activation, suggests that lipin-1 may also participate in mitochondrial metabolism in skeletal muscle [24, 25]. Until now, most investigations about the function of lipin-1 in skeletal muscle are performed in vivo, which involved with tissue and tissue communications. The in vitro study is necessary to elucidate the exact effect of lipin-1 and its relationship with lipid metabolism in skeletal muscle.

In the present study, we explored the relationship between lipin-1 and insulin sensitivity in C2C12 myotubes using siRNA transfection, and further investigated whether lipin-1 played a role in the development of lipid induced insulin resistance.
We also sought to identify the underlying mechanism according to the function of lipin-1 in skeletal muscle lipid metabolism.

\section{Material and methods}

\subsection{Inhibitors}

Fumonisin B1 (FB1) was from Santa Cruz Biotechnology and myriocin was from Dalian Meilun Biology Technology Co. PP2A inhibitor okadaic acid was purchased from Beyotime.

\subsection{Cell culture}

C2C12 myoblasts, purchased from the American Type Culture Collection were cultured in Dulbecco's modified Eagle's medium (DMEM) supplemented with $10 \%$ FBS, 100 units $/ \mathrm{ml}$ penicillin, and $100 \mu \mathrm{g} / \mathrm{ml}$ streptomycin at $37^{\circ} \mathrm{C}$ with $5 \% \mathrm{CO}_{2}$. Upon reaching $100 \%$ confluence, cells were transferred to differentiation medium (DMEM with 2\% horse serum) for 4 days.

\subsection{Transfection of siRNA}

Lipin-1 siRNA was purchased from Santa Cruz Biotechnology. siRNA was transfected using Lipofectamine RNAiMAX (Invitrogen Life Technologies) according to the manufacturer's instructions. Transfection was conducted on day 2 or day 3 of the differentiation in $\mathrm{C} 2 \mathrm{C} 12$ cells. Assays were done at $48 \mathrm{~h}$ or $24 \mathrm{~h}$ after transfection when myoblasts were fully differentiated.

\subsection{Palmitate treatment in $\mathrm{C} 2 \mathrm{C} 12$ myotubes}

Palmitate/BSA solution was prepared as previously described [26]. Briefly, palmitate (Sigma-Aldrich) was dissolved in $0.1 \mathrm{mM} \mathrm{NaOH}$ at $70^{\circ} \mathrm{C}$ and diluted $1: 20$ in $5 \%(\mathrm{w} / \mathrm{v})$ fatty acid free BSA (PAA Laboratories) in PBS to make a $5 \mathrm{mM}$ palmitate/ $5 \%$ BSA solution. The solution was then incubated in $56^{\circ} \mathrm{C}$ water bath for $10 \mathrm{~min}$, cooled to room temperature and filtered. Then, the palmitate/BSA solution was diluted in DMEM to final concentration of $0.75 \mathrm{mM}$ palmitate/ $0.75 \%$ BSA or $0.5 \mathrm{mM}$ palmitate/ $0.75 \%$ BSA. Differentiated C2C12 myotubes in 24-well plates was then incubated with above solutions for $24 \mathrm{~h}$ with $10 \mathrm{nM}$ insulin stimulation for the last $30 \mathrm{~min}$.

\subsection{RNA extraction and quantitative RT-PCR analysis}

RNA was extracted using Trizol reagent (Invitrogen Life Technologies) and reverse transcript with PrimeScript ${ }^{\mathrm{TM}} \mathrm{RT}$ reagent Kit with gDNA Eraser (Takara). mRNA level was quantified by quantitative RT-PCR using SYBR Premix Ex Taq kit (Takara) on ABI fast 7500 System (Invitrogen Life Technologies). 
The primers for real-time PCR were synthesized by Invitrogen Life Technologies, and described in Table 1. All the quantitative real time PCRs were normalized to GAPDH.

\subsection{Western blot analysis}

Western blot analysis was performed as previously described [27]. Equal protein samples were subjected into separation by SDS-PAGE and were transferred to PVDF membranes. After being blocked with $7.5 \%$ milk in TBST, membranes were incubated with primary antibodies target phospho-Akt (Ser $\left.{ }^{473}\right)$, phospho-Akt (Thr $\left.{ }^{308}\right)$, phosphor-GSK-3 $\beta$ (Ser $\left.{ }^{9}\right)$, Akt, lipin-1, MYH, myogenin and GAPDH overnight at $4^{\circ} \mathrm{C}$. Primary antibodies are purchased from Cell signaling Technology, except MYH and myogenin antibodies were from Santa Cruz Biotechnology and lipin-1 antibody was from Novus Biological. Next, membranes were incubated with anti-rabbit IgG HRP-linked antibody (Bio-Rad) for $2 \mathrm{~h}$ at room temperature, washed with TBST and visualized by ECLTM Prime Western Blotting Detection Reagent (GE healthcare). Band intensities were measured using quantity one (Bio-Rad) and normalized to GAPDH.

\subsection{2 -Deoxyglucose uptake}

After serum starved for $6 \mathrm{~h}, \mathrm{C} 2 \mathrm{C} 12$ myotubes were incubated in KRHB (130 mmol/l $\mathrm{NaCl}, 5$ $\mathrm{mmol} / 1 \mathrm{KCl}, 1.3 \mathrm{mmol} / 1 \mathrm{MgSO}_{4}, 1.3 \mathrm{mmol} / 1 \mathrm{CaCl}_{2}$, $25 \mathrm{mmol} / 1$ HEPES, $\mathrm{pH}$ 7.4) with or without 100 $\mathrm{nmol} / 1$ insulin for $20 \mathrm{~min}$, followed by incubation with $0.05 \mathrm{mmol} / 1$ 2-deoxy-D-glucose and $1.85 \times 10^{4}$ $\mathrm{Bq} / \mathrm{ml}$ 2-deoxy-D-[1,2-3H] glucose for $10 \mathrm{~min}$. Radioactivity was determined by liquid scintillation counting (Perkin Elmer Trilu) and normalized to protein concentration.

\subsection{ATP assay}

The ATP content was measured using a luciferase-based luminescence assay kit (Beyotime) according to the manufacturer's instructions and

Table 1. The primers for real-time PCR.

\begin{tabular}{lll}
\hline $\begin{array}{l}\text { mouse } \\
\text { gene }\end{array}$ & Forward primer & Reverse primer \\
\hline $\begin{array}{l}\text { Lipin-1a } \\
\text { Lipin-1 } \beta\end{array}$ & CAGCCTGCCCAGCCCCAGTCCTT & GCAGCCTGTGGCAATTCA \\
GAPDH & GGTCGGTGTGAACGGATTTGG & TCAGCCTGTGGCAATTCA \\
PGC-1a & TCTGAAAGGGCCAAACAGAG & GTAAATCACACGGCGCTCTT \\
PGC-1 & GCCCTGTCCCAGAGTGAAAG & GCATGTAGCGAATGAGCTGTA \\
PPARa & GGCTTCTTTCGGCGAACTATT & CCGATCACACTTGTCGTACAC \\
mtTFA & GCTGATGGGTATGGAGAAG & GAGCCGAATCATCCTTTGC \\
NRF1 & GCCGTCGGAGCACTTACT & CTGTTCCAATGTCACCACC \\
NRF2 & AGCAGGACATGGAGCAAGTT & TTCTTTTTCCAGCGAGGAGA \\
SIRT1 & AGGGAACCTTTGCCTCATCTA & GTGCCACTGTCACTGTTACTGC \\
Mcad & GAGAAGAAGGGTGACGAGTATGT & GGGTACTTTAGGATCTGGGTTAG \\
Acox & TGACCCCAAGACCCAAGAGTTC & AAAGTGGAAGGCATAGGCGG \\
\hline
\end{tabular}

normalized to protein concentration.

\subsection{ROS assay}

The ROS production was determined using Reactive Oxygen Species Assay Kit (Beyotime). Briefly, after serum starved for $6 \mathrm{~h}$, the cells were washed with warm PBS twice and incubated with pre-warmed $\mathrm{DCFH}-\mathrm{DA}$ at $37^{\circ} \mathrm{C}$ for $20 \mathrm{~min}$. After washed with PBS twice, cells were collected with PBS supplement with $1 \%$ Triton, spun at $12000 \mathrm{rpm}$ for $10 \mathrm{~min}$. Fluorescence of supernatant was determined at lengths of $488 \mathrm{~nm} / 525 \mathrm{~nm}$ (excitation/emission) and normalized to protein concentration.

\subsection{TAG measurement}

Cells were harvested with deionized water. After sonication, total TAG content in the lysate was determined using commercial kits (East Ou Jin Ma Biotech). Absorbance was normalized to protein concentration.

\subsection{Ceramide analysis}

Lipid extraction was conducted according to the method of Dianna et al. with modifications [28]. Briefly, cells were collected with deionized water and sonicated. After protein concentration measurement, an aliquot equivalent to $300 \mu \mathrm{g}$ protein was used for lipid extraction. Ceramide C17 was used as internal standard and added before lipid extraction. $700 \mu 1$ methanol/chloroform (1:2) was added to cell lysates, vortexed and shaked at $4^{\circ} \mathrm{C}$ for $1 \mathrm{~h}$. Mixture was spun for $10 \mathrm{~min}$ at $10000 \mathrm{rpm}$. The lower layer was transferred to a new glass tube and the left layers were sonicated for second extraction. The chloroform solvent was dried and reconstituted with methanol. LC-MS/MS was used to measure intracellular contents of ceramide C16, C22 and C24 [28]. Ceramide standards, purchased from Avanti Polar Lipids were dissolved in a 99.8/0.2 mixture of ethanol/formic acid, further dilutions were made with methanol. The LC-MS/MS measurements were conducted on an AB6500 triple quadrupole mass spectrometer (AB SCIEX) coupled to a Waters UPLC system (Waters). Liquid chromatographic separation was obtained using $1.0 \mu \mathrm{l}$ injections of samples onto Waters Acquity UPLC BEH C18 Column $\left(100^{*} 2.1 \mathrm{~mm}, 1.7 \mu \mathrm{m}\right)$. The autosampler temperature was set at $4^{\circ} \mathrm{C}$ and the column was maintained at $50^{\circ} \mathrm{C}$ during the whole analysis. Gradient elution mobile phases consisted of B $(0.1 \%$ formic acid in methanol). Gradient elution $(400 \mu \mathrm{l} / \mathrm{min})$ was $100 \%$ B which was maintained for $5.5 \mathrm{~min}$. The AB6500 triple quadrupole mass spectrometer was set for electrospray ionization (ESI). The electrospray interface was operated in positive ion mode. 
The source parameters were as follows: capillary voltage, $5500 \mathrm{~V}$; curtain gas 25 psi; gas temperature, $400^{\circ} \mathrm{C}$; ion Source Gas 1, 55 psi; ion Source Gas 2, 55 psi; collision gas, 9 psi. Levels of ceramide were analyzed by multiple reactions monitoring (MRM). In MRM mode, detection of each compound is based on fragmentation of the precursor ion $[\mathrm{M}+\mathrm{H}]+$ to yield a prominent product ion.

\subsection{DAG analysis}

The levels of DAG species were measured using UPLC/Q-TOF MS method as previous described [29]. Briefly, after lipid extraction, the level of DAG species was measured using UPLC/Q-TOF MS. Acquity UPLC system (Waters Corp.) on an Acquity UPLC HSS T3 column $(2.1 \mathrm{~mm} \times 100 \mathrm{~mm}, 1.8 \mu \mathrm{m}$, Waters Corp.) was used for separation of DAG profile in cell samples. The mobile phase was a mixture of (A) $5 \mathrm{mM}$ ammonium acetate and (B) methanol and was delivered at $0.5 \mathrm{~mL} / \mathrm{min}$. For the semi-quantitative analysis of DAGs, the mass spectrometric detection was conducted on an API 4000 triplequadrupole mass spectrometer (Applied Biosystems) equipped with an ESI. The electrospray interface was operated in the positive ionization mode. The MRM transitions were established based on the high resolution mass spectrometric analysis of DAGs.

\subsection{Statistical analysis}

Results were presented as means \pm SEM. $P$ value was analyzed by Student's t test. Values of $P<0.05$ were considered statistically significant $\left({ }^{*} P<0.05 ;{ }^{* *} P\right.$ $<0.01 ;{ }^{* * *} P<0.001$ )

\section{Results}

\subsection{Downregulation of lipin-1 induces insulin resistance in $\mathrm{C} 2 \mathrm{C} 12$ myotubes}

To evaluate the effect of lipin-1 on insulin sensitivity in skeletal muscle, lipin-1 silencing was performed in $\mathrm{C} 2 \mathrm{C} 12$ myotubes. As shown in Figure $1 \mathrm{~A}$ and $\mathrm{B}$, transfection of $\mathrm{C} 2 \mathrm{C} 12$ myotubes with specific lipin-1 siRNA decreased protein level of lipin- 1 by $40 \%$, and no difference could be observed between Negative Control (N.C) siRNA and control group. Moreover, RT-PCR analysis showed that lipin-1 siRNA targeted both isoforms of lipin-1 and decreased mRNA expression of lipin-1 $\alpha$ and lipin-1 $\beta$ by $46 \%$ and $65 \%$, respectively (Figure 1C). Lipin-1 silencing didn't change the protein expression of myogenin and $\mathrm{MYH}$, two myoblast differentiation markers, suggested that the differentiation of $\mathrm{C} 2 \mathrm{C} 12$ myotubes was unaltered (Figure 1A). Insulin stimulation in N.C siRNA cells led to $110 \%$ increase in phosphorylation of Akt (Ser ${ }^{473}$ and $\mathrm{Thr}^{308}$ ) and 39\% increase in glucose uptake, indicating normal insulin sensitivity in $\mathrm{C} 2 \mathrm{C} 12$ myotubes after transfection. Lipin-1 silencing showed no effect on Akt protein level, but significantly decreased insulin stimulated phosphorylation of Akt $\left(\mathrm{Ser}^{473}\right)$ and Akt $\left(\mathrm{Thr}^{308}\right)$ to $64 \%$ and $61 \%$ of N.C siRNA, respectively (Figure 1D). Meanwhile, insulin stimulated phosphorylation of GSK-3 $\beta\left(\right.$ Ser $\left.^{9}\right)$ was attenuated. Moreover, downregulation of lipin-1 in $\mathrm{C} 2 \mathrm{C} 12$ myotubes decreased insulin-stimulated glucose uptake by $25 \%$ compared with N.C siRNA (Figure 1E). These results suggest that downregulaion of lipin-1 blunts insulin action and impairs insulin-stimulated glucose uptake in $\mathrm{C} 2 \mathrm{C} 12$ myotubes.

\subsection{Lipin- 1 expression was downregulated in palmitate-induced insulin resistance in $\mathrm{C} 2 \mathrm{C} 12$ myotubes}

We further detected the abundance of lipin-1 protein in $\mathrm{C} 2 \mathrm{C} 12$ myotubes under insulin resistant condition. To imitate insulin resistance, $\mathrm{C} 2 \mathrm{C} 12$ myotubes were incubated with different concentrations of palmitate for 24h. Palmitate treatment at the dose of 0.5 and $0.75 \mathrm{mM}$ had no effect on Akt protein level, but significantly reduced insulin stimulated Akt phosphorylation ( $\mathrm{Ser}^{473}$ and $\mathrm{Thr}^{308}$ ), suggesting impaired insulin sensitivity in these cells (Figure 2B and C). $0.5 \mathrm{mM}$ palmitate treatment tended to decreased lipin-1 protein level, while $0.75 \mathrm{mM}$ palmitate treatment significantly decreased lipin-1 protein level in $\mathrm{C} 2 \mathrm{C} 12$ myotubes to $64 \%$ of BSA control (Figure 2D).

\subsection{Downregulation of lipin- 1 remodels intracellular lipid profile in $\mathrm{C} 2 \mathrm{C} 12$ myotubes}

Since lipin-1 accounts for almost all PAP1 activity in skeletal muscle, we examined whether lipin-1 silencing would remodel intracellular lipid profile in $\mathrm{C} 2 \mathrm{C} 12$ myotubes. First, the levels of two important lipid intermediates, DAG and ceramide, which are known to inhibit insulin signaling pathway were detected. As shown in Figure 3A, lipin-1 silencing significantly reduced the contents of several DAG species, including 14:0/16:0, 16:1/16:1, 16:0/18:2, 18:2/18:2, 18:1/18:2, 18:1/18:1 and 18:0/18:0). The profiles of ceramide were analyzed by LC-MS/MS, and three kinds of ceramides, including C16:0, C22:0 and C24:0 were identified as the most abundant species in $\mathrm{C} 2 \mathrm{C} 12$ myotubes. Lipin-1 silencing significantly increased the contents of C16:0, C22:0 and C24:0 ceramides by $32 \%, 30 \%$ and $45 \%$ compared with N.C siRNA control (Figure 3B). Meanwhile, intracellular TAG was decreased to $80 \%$ of N.C siRNA control upon lipin-1 silencing (Figure 3C). 
A

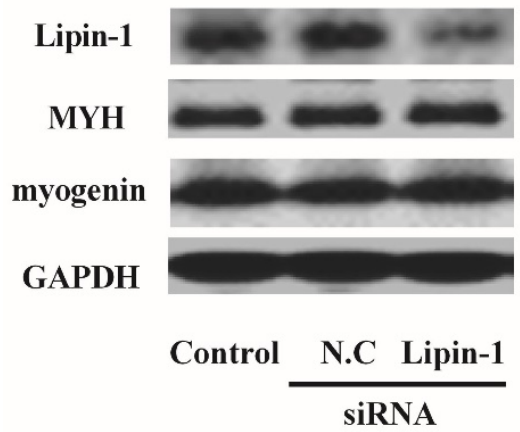

B

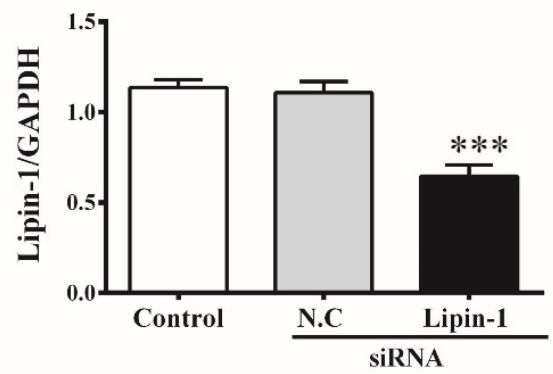

C

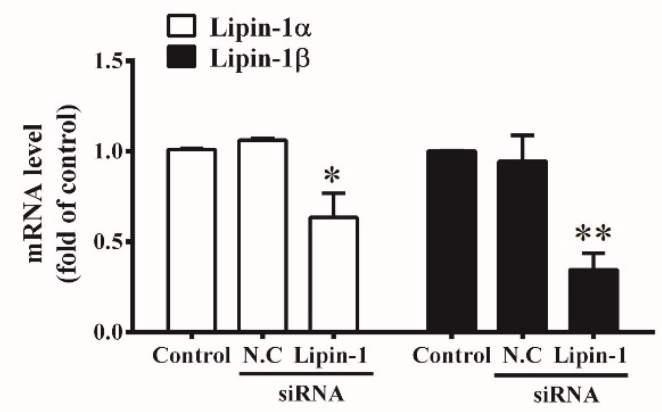

$\mathbf{E}$

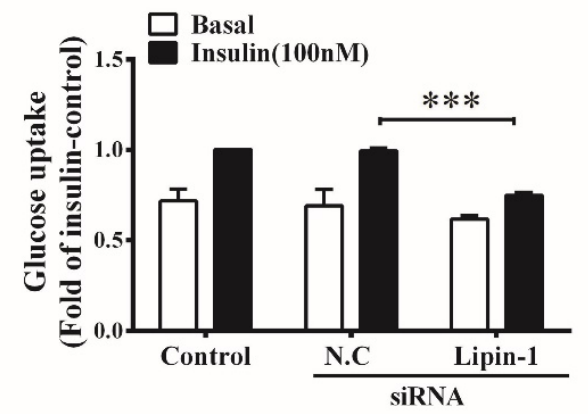

D

\section{Insulin}

p-Akt-473

p-Akt-308

Akt

pGSK3 $\beta \quad--\infty-\cdots$

GAPDH
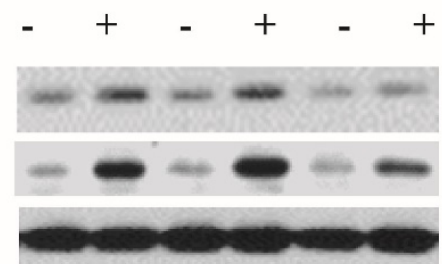

Control $\frac{\text { N.C } \quad \text { Lipin-1 }}{\text { siRNA }}$
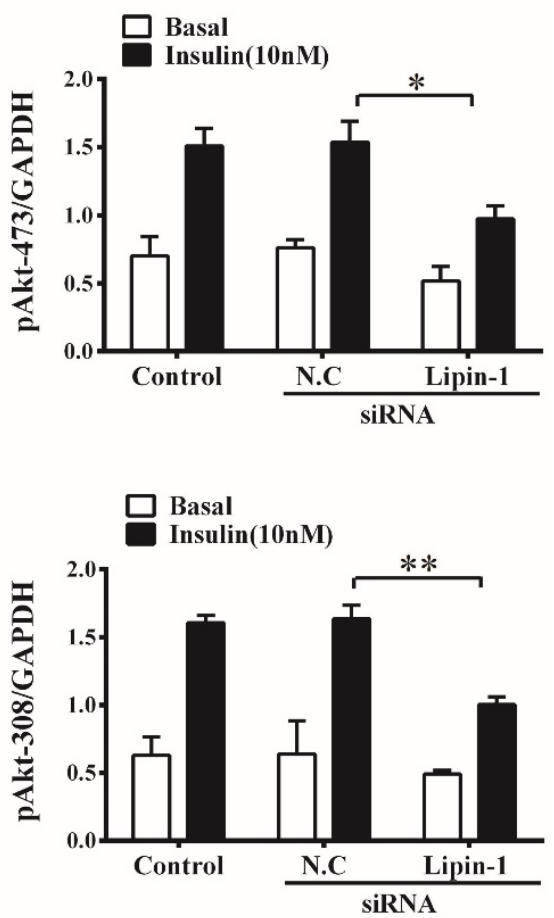

Figure 1. Lipin-1 silencing induces insulin resistance in C2C12 myotubes. C2C12 myotubes were transfected with lipin-1 siRNA, N.C siRNA or control (without siRNA), and were analyzed $48 \mathrm{~h}$ post transfection following serum starvation for $6 \mathrm{~h}$. (A, B) Cell lysates were subjected to western blot analysis for protein level of lipin-1, MYH and myogenin. (C) Confirmation of lipin-1 silencing by RT-PCR. (D) Cell lysates prepared after siRNA transfection were subjected to western blot analysis for phosphorylation of Akt (Ser473 and Thr ${ }^{308}$ ) and GSK-3 (Ser $\left.{ }^{9}\right)$ in the absence or presence of $10 \mathrm{nM}$ insulin for 30 min. (E) After $6 \mathrm{~h}$ serum starvation, C2C12 myotubes were stimulated with or without $100 \mathrm{nM}$ insulin for $30 \mathrm{~min}$ and the glucose uptake was assessed as described in method. Values represent the mean \pm SEM from three or four independent experiments. $*_{p}<0.05, *_{p}<0.01, *^{* *} p<0.001$ vs N.C siRNA or the indicated control. N.C, negative control. 
A

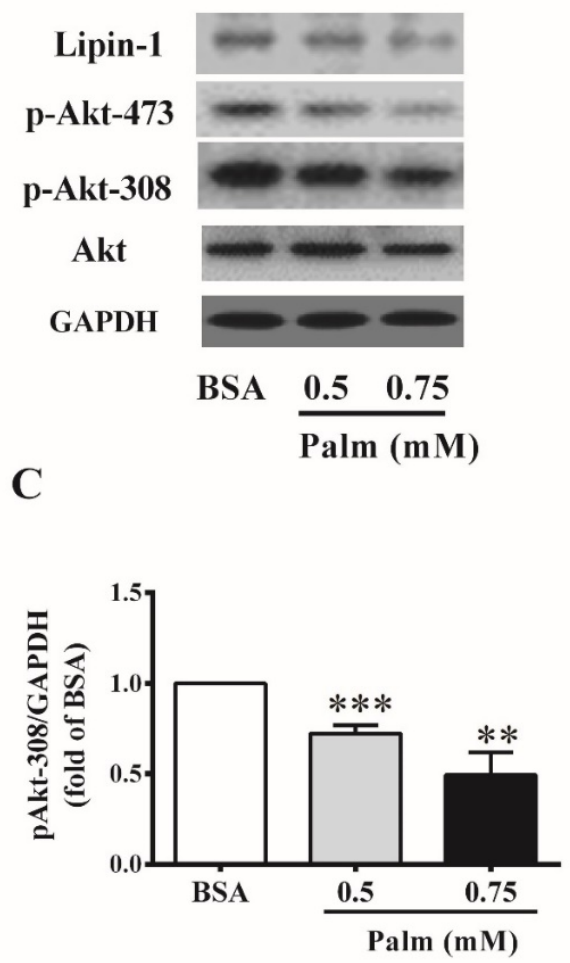

B

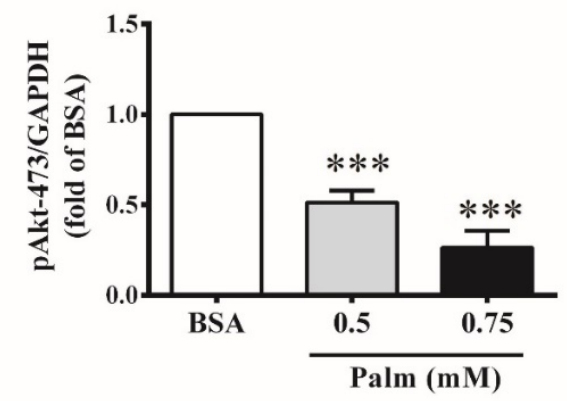

D

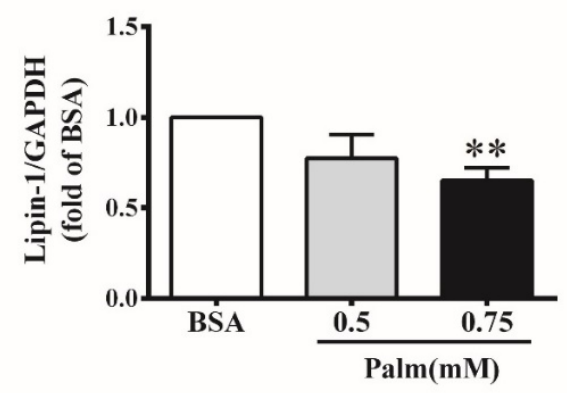

Figure 2. Lipin-1 protein expression in palmitate-induced insulin resistance in $\mathbf{C 2 C 1 2}$ myotubes. $\mathrm{C} 2 \mathrm{C} 12$ myotubes were exposed to different concentrations of palmitate for $24 \mathrm{~h}$ and insulin stimulation for the last $30 \mathrm{~min}$. Protein abundance of lipin-1 and phosphorylation of $A$ kt (Ser ${ }^{473}$ and Thr 308$)$ was evaluated by western blot (A). Quantified values of Akt Ser ${ }^{473}$ (B), Thr ${ }^{308}$ (C) and lipin-1 (D) represent the mean \pm SEM from three or four independent experiments. $* * p<0.01$, *** $p<0.001$ vs BSA. Palm, palmitate.

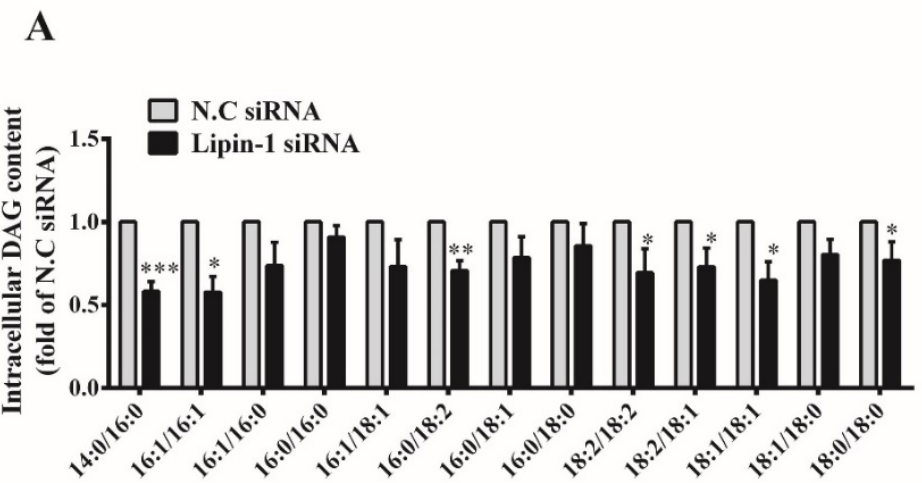

B

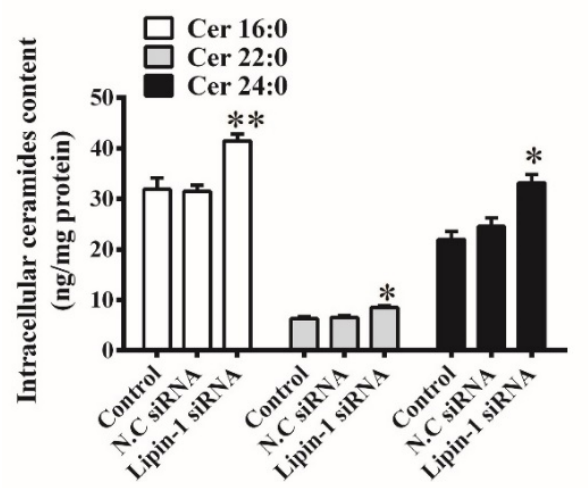

C

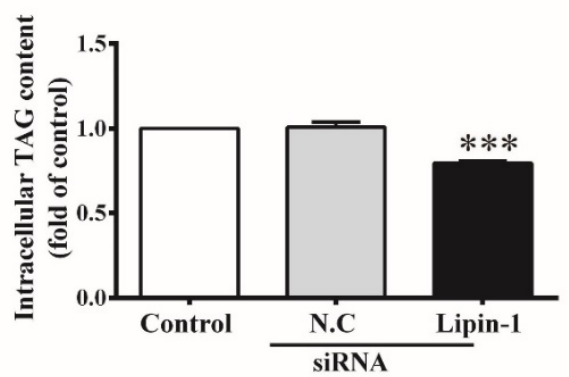

Figure 3. Effect of lipin-1 silencing on intracellular lipid profile in $\mathbf{C 2 C 1 2}$ myotubes. $\mathrm{C} 2 \mathrm{C} 12$ myotubes were transfected with lipin-1 siRNA for $48 \mathrm{~h}$ following serum starvation for $6 \mathrm{~h}$. Total lipids were extracted and measured by LC-MS/MS to quantify DAG (A) and ceramide (B). (C) TAG was analyzed by commercial kits. Values represent the mean \pm SEM from three or four independent experiments. $*_{p}<0.05, * * p<0.01$ and $* * * p<0.001$ vs N.C siRNA. N.C, negative control. 
A
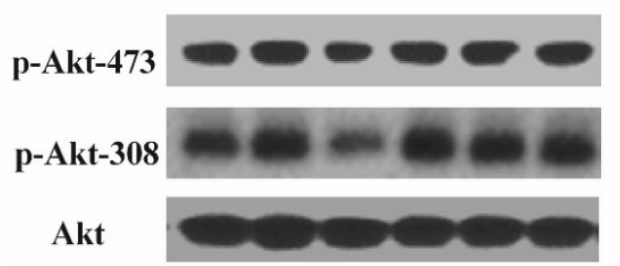

GAPDH

Control N.C Lipin-1 Control N.C Lipin-1

FB 1
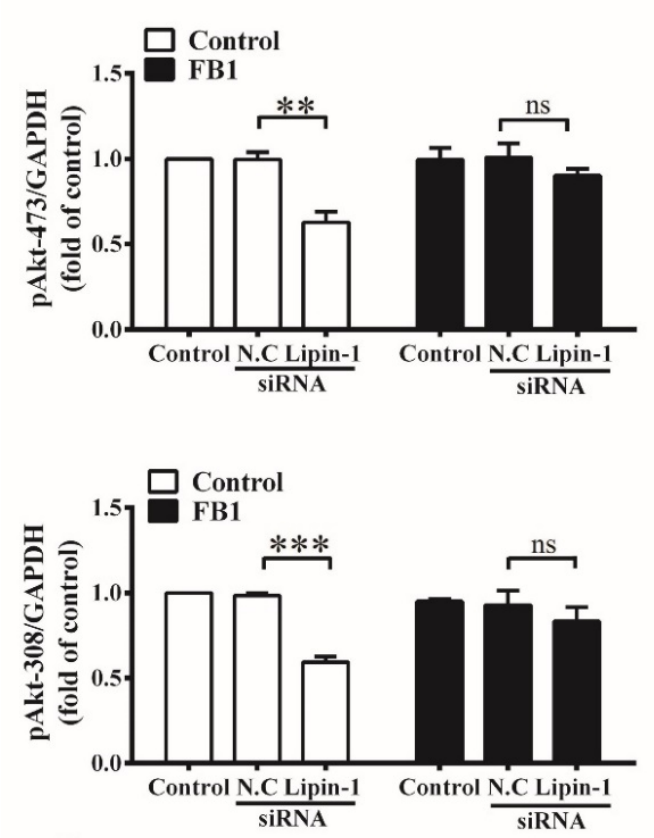

C

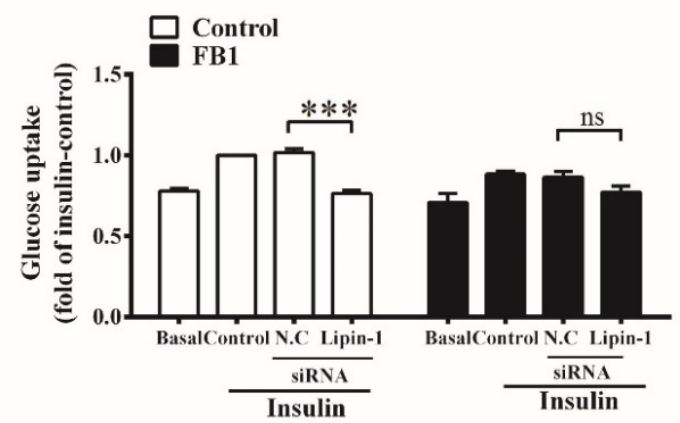

B
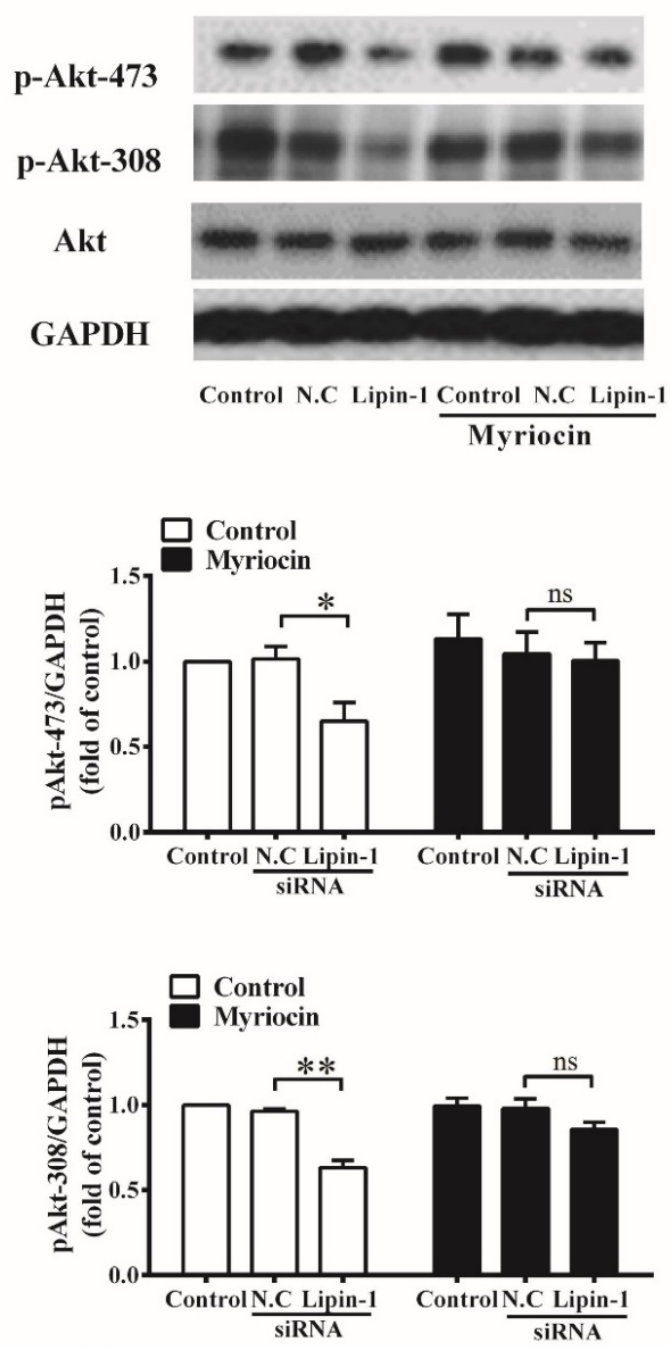

D

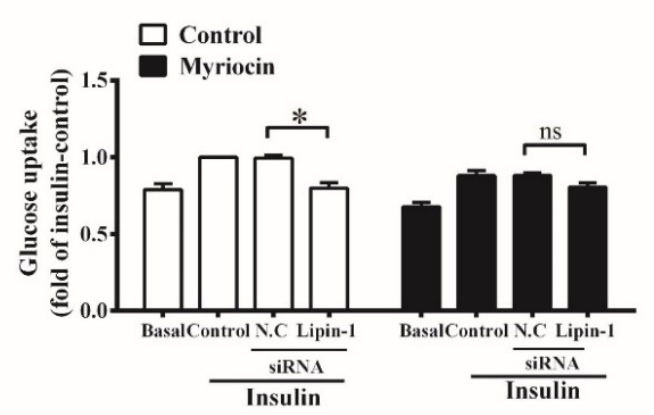

Figure 4. Inhibition of ceramide synthesis ameliorates insulin resistance induced by lipin-1 silencing. $C 2 C 12$ myotubes were incubated with or without $10 \mu M$ FB 1 $(A, C)$ or $3 \mu \mathrm{M}$ myriocin (B, D) before siRNA transfection, and the insulin stimulated Akt phosphorylation and glucose uptake were assessed after serum starvation for $6 \mathrm{~h}$. Values represent the mean \pm SEM from three or four independent experiments. $* p<0.05$, ** $p<0.01$ and *** $p<0.001$ vs the indicated control. FB1, Fumonisin B1. N.C, negative control.

\subsection{Inhibition of ceramide synthesis ameliorates insulin resistance induced by lipin-1 downregulation}

Serine palmitoyltransferase (SPT) and ceramide synthases are key enzymes involved in ceramide synthesis. To investigate the involvement of elevated ceramide content in the development of insulin resistance caused by lipin-1 silencing, $\mathrm{C} 2 \mathrm{C} 12$ myotubes were incubated with $10 \mu \mathrm{M}$ ceramide synthases inhibitor FB1 or $3 \mu \mathrm{M}$ SPT inhibitor myriocin (Figure 4) before siRNA transfection, and insulin stimulated Akt phosphorylation and glucose uptake were detected. As shown in Figure 4A and 4B, 
lipin-1 silencing significantly reduced the insulin stimulated phosphorylation of Akt ( $\mathrm{Ser}^{473}$ and $\left.\mathrm{Thr}^{308}\right)$, and these effects were blocked by the presence of FB1 or myriocin. Accordingly, lipin-1 downregulation failed to impaired insulin-stimulated glucose uptake under FB1 or myriocin pretreatment condition (Figure 4C and 4D). These results suggested that elevated ceramide content contributed to the insulin resistance induced by lipin-1 silencing in C2C12 myotubes.

\subsection{Inhibition of PP2A activity ameliorates insulin resistance induced by lipin- 1 downregulation}

In $\mathrm{C} 2 \mathrm{C} 12$ myotubes, ceramide activates PP2A, which is known to dephosphorylate Akt. Therefore, inhibitor of PP2A, okadaic acid was then applied to further explore the role of increased intracellular ceramide accumulation in the development of insulin resistance under lipin-1 silencing condition. Lipin-1 silencing decreased insulin stimulated phosphorylation of Akt (Ser ${ }^{473}$ and $\mathrm{Thr}^{308}$ ) to $73 \%$ and $70 \%$ of N.C siRNA control, and these effects were abolished in the present of OKA treatment. Meanwhile, lipin-1 silencing significantly reduced insulin stimulated glucose uptake to $81 \%$ of N.C siRNA control, and this effect was blocked by the pretreatment of OKA (Figure 5). In order to confirm lipin-1 downregulation do activate PP2A through ceramide accumulation, $\mathrm{C} 2 \mathrm{C} 12$ myotubes were incubated with C16:0 ceramide, which was found to be the most abundant ceramide specie of $\mathrm{C} 2 \mathrm{C} 12$ myotubes in Figure 3B. As shown in Figure 5E and 5F, C16:0 ceramide treatment impaired insulin stimulated Akt phosphorylation, and these effects were abrogated by the presence of OKA. These results indicated that PP2A activation was responsible for insulin resistance caused by lipin-1 downregulation in C2C12 myotubes.

\subsection{Downregulation of lipin-1 impairs mitochondrial function in $\mathbf{C 2 C 1 2}$ myotubes}

Lipin-1 was reported to act as a transcriptional co-regulator of PGC-1a/PPARa which plays a critical role in mitochondria biogenesis and metabolism in liver [18]. Meanwhile, mitochondrial dysfunction can lead to accumulation of ceramide [30]. Therefore, we further investigated the effect of lipin-1 silencing on mitochondrial function in $\mathrm{C} 2 \mathrm{C} 12$ myotubes. As shown in Figure 6A, lipin-1 silencing in $\mathrm{C} 2 \mathrm{C} 12$ myotubes reduced mRNA levels of PGC-1a and PPARa to $49 \%$ and $70 \%$ of N.C siRNA control, respectively. Accordingly, PGC-1a target genes involved in mitochondria biogenesis and metabolism in skeletal muscle, including PGC-1 $\beta$, NRF1, NRF2, the mitochondrial transcription factor (mtTFA), and several genes involved in fatty acid oxidation, SIRT1, Acox and Mcad were significant suppressed upon lipin-1 silencing. In addition, lipin-1 silencing in C2C12 myotubes decreased ATP production (Figure 6B) and slightly increased ROS production (Figure 6C). These results indicated that mitochondrial function was impaired and mitochondrial metabolism was weakened upon lipin-1 silencing in C2C12 myotubes.

\section{Discussion}

Lipin-1 has been implicated in the regulation of lipid and energy metabolism in several tissues, including liver and adipose tissue. However, the function of lipin-1 in skeletal muscle has not been completely characterized. In the present study, the effect of lipin-1 on insulin sensitivity and lipid metabolism was investigated in $\mathrm{C} 2 \mathrm{C} 12$ myotubes. Our study showed that lipin-1 downregulation impaired insulin stimulated Akt phosphorylation and glucose uptake, and these effects might be attributed to the disturbance of lipid homeostasis caused by lipin-1 silencing in $\mathrm{C} 2 \mathrm{C} 12$ myotubes.

Lipin-1 is highly expressed in mouse skeletal muscle and alterations in lipin-1 expression levels might produce important pathophysiological effect $[23,31]$. In this study, lipin-1 siRNA transfection was performed to explore its effect on insulin sensitivity in C2C12 myotubes. Two other lipin family proteins, lipin-2 and lipin-3 are reported to compensate for the absence of lipin-1[22, 32], however, we didn't observe mRNA level variation of lipin-2 and lipin-3 in this study (data not shown). Lipin-1 knockdown significantly decreased insulin stimulated Akt phosphorylation, suggesting insulin signaling pathway had been impaired. Furthermore, insulin stimulated glucose uptake in skeletal muscle was suppressed by lipin-1 knockdown. Lipin-1 was reported to be up-regulated during $\mathrm{C} 2 \mathrm{C} 12$ myoblast differentiation, and knockdown of lipin-1 expression by infection with adenovirus (shLpin1) before initiation of differentiation in $\mathrm{C} 2 \mathrm{C} 12$ myoblast would suppress myogenic differentiation [33]. However, in our study, lipin-1 silencing didn't change the protein expression of myogenin and $\mathrm{MYH}$ in $\mathrm{C} 2 \mathrm{C} 12$ myotubes, suggested that the myoblast differentiation wasn't affected. The discrepancy may be due to the different time of transfection conducting, since we performed the lipin-1 silencing at day 2 or day 3 after the initiation of differentiation. Therefore, our results showed that lipin-1 plays an important role in the regulation of insulin sensitivity, and downregulation of lipin-1 impaired insulin stimulated glucose uptake and Akt phosphorylation, but had no effect on differentiation of $\mathrm{C} 2 \mathrm{C} 12$ myotubes. 
A

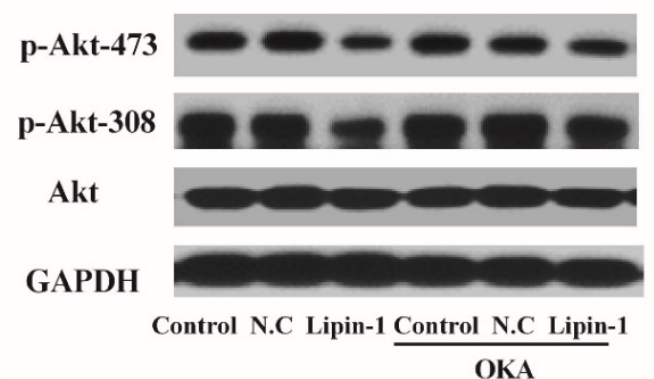

C

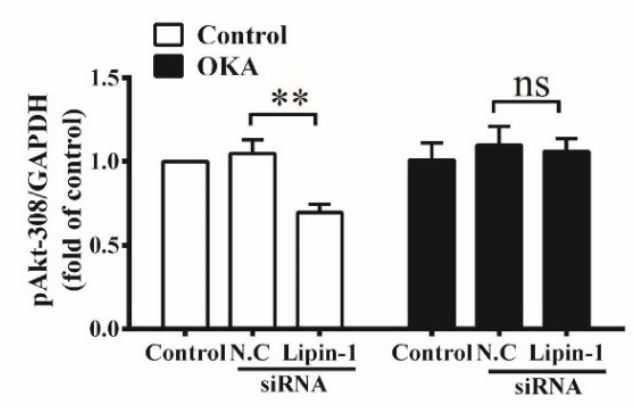

$\mathbf{E}$

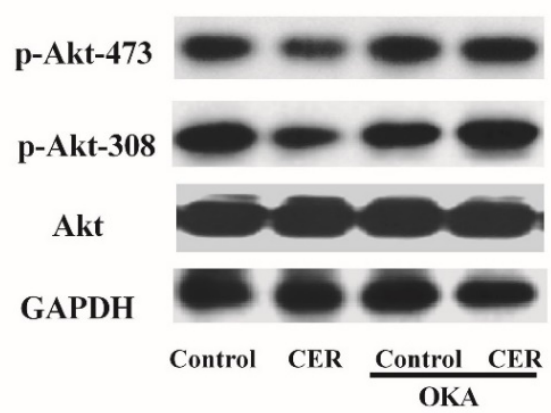

B

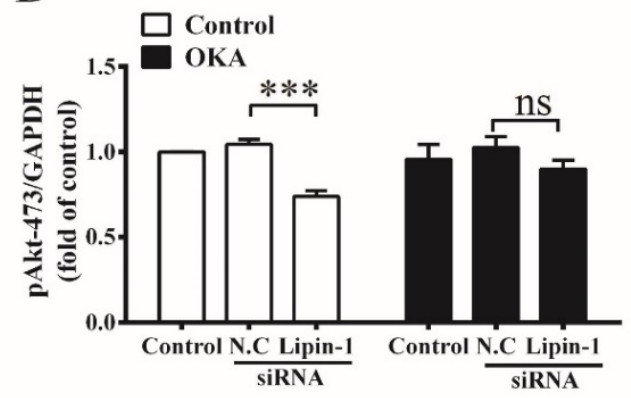

D

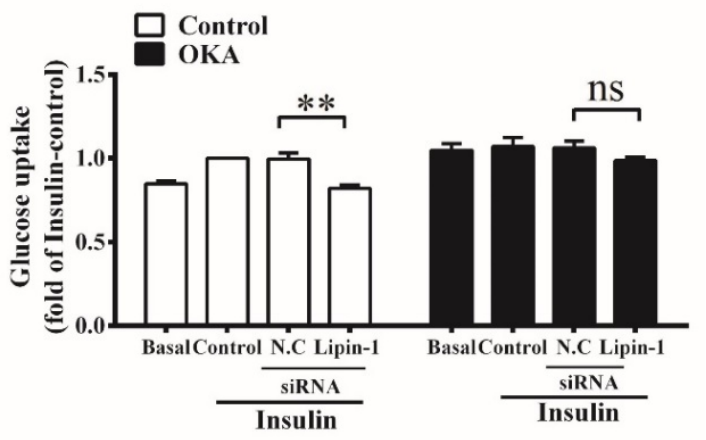

F

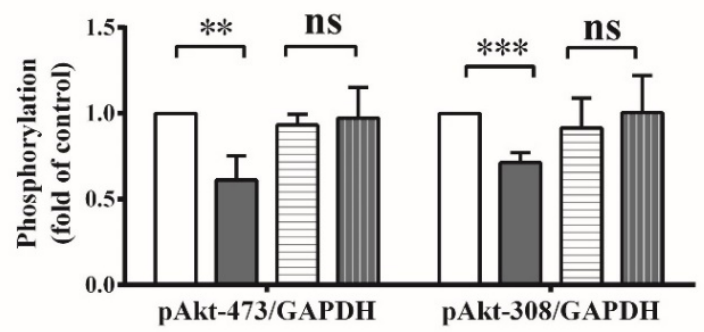

Figure 5. Inhibition of PP2A activity ameliorates insulin resistance induced by lipin-1 silencing. $\mathrm{C} 2 \mathrm{C} 12$ myotubes were incubated with or without $10 \mathrm{nM}$ okadaic acid before siRNA transfection, and the insulin stimulated Akt phosphorylation (A, B, C) and glucose uptake (D) were assessed after serum starvation for 6 h. C2C12 myotubes were exposed to $50 \mu \mathrm{M} \mathrm{C16:0} \mathrm{ceramide} \mathrm{for} 24 \mathrm{~h}$ and insulin stimulation for the last $30 \mathrm{~min}$ in the absence or presence of $10 \mathrm{nM}$ okadaic acid and phosphorylation of Akt (Ser 473 and $\mathrm{Thr}^{308}$ ) was evaluated by western blot $(\mathrm{E}, \mathrm{F})$. Values represent the mean $\pm \mathrm{SEM}$ from three or four independent experiments. $* * p<0.01$ and $* * * p<0.001$ vs the indicated control. OKA, okadaic acid. N.C, negative control. Cer, C16:0 ceramide.

Connection between decreased lipin-1 expression and insulin resistance in skeletal muscle was further studied by detecting the level of lipin-1 protein under insulin resistant condition. Palmitate is a major factor contributing to the development of skeletal muscle insulin resistance under lipid oversupply condition, such as obesity and lipodystrophy [34]. The insulin stimulated Akt phosphorylation was significantly decreased after palmitate challenge in C2C12 myotubes, suggesting the occurrence of insulin resistance. Meanwhile, the expression of lipin-1 protein was significantly reduced along with the decreased insulin sensitivity, which suggested that lipin-1 might participate in the development of insulin resistance in skeletal muscle. Insulin resistance in skeletal muscle is tightly connected with lipid intermediates elevation induced by lipid metabolism dysregulation [35]. Lipin-1 was report to account for almost all of the PAP1 activity which catalyzes the dephosphorylation of PA to DAG in skeletal muscle [28]. Moreover, as the substrate for TAG biosynthesis, the decreased DAG that results from PAP1 inhibition would reduce the TAG content, and this has been confirmed by the impaired TAG synthesis in lipin-1-deficient fld mouse [31]. Therefore, we evaluated the effect of lipin-1 silencing on DAG and TAG levels in C2C12 myotubes. Upon lipin-1 silencing, intraceullar DAG level was reduced. 
Meanwhile, the TAG level was also decreased by lipin-1 silencing in $\mathrm{C} 2 \mathrm{C} 12$ myotubes. DAG accumulation in skeletal muscle was associated with the occurrence of insulin resistance, and the reduced DAG contents can't explain the impaired insulin stimulated glucose uptake and Akt phosphorylation caused by lipin-1 silencing. Ceramide is another toxic lipid intermediate that lead to insulin desensitization [36]. Inhibition of TAG synthesis in skeletal muscle may increase ceramide accumulation. Using LC-MS/MS analysis, we found that C16:0, C22:0 and C24:0 ceramides were the most abundant ceramide species in $\mathrm{C} 2 \mathrm{C} 12$ myotubes. Moreover, the levels of all these ceramide species were elevated after lipin-1 silencing. Therefore, lipin- 1 is crucial for lipid homeostasis in skeletal muscle. Downregulation of lipin-1 expression decreased intracellular DAG and TAG levels, but elevated ceramide accumulation in C2C12 myotubes.

Inhibition of ceramide synthesis is reported to ameliorate high fat diet induced skeletal muscles insulin resistance. Intraperitoneal administration of myriocin, a SPT inhibitor could significantly reduce ceramide de novo synthesis in rat skeletal muscles and associated with the improved whole body glucose homeostasis [37-39]. In our study, C2C12 myotubes were treated with SPT inhibitor myriocin or ceramide synthase inhibitor FB1 before siRNA transfection to further investigate the contribution of elevated ceramide content in the development of insulin resistance induced by lipin-1 downregulation. The results showed that both of myriocin and FB1 protected $\mathrm{C} 2 \mathrm{C} 12$ myotubes from the detrimental effect of lipin-1 silencing, including decreased insulin stimulate Akt phosphorylation and glucose uptake. Ceramide engages different pathways to inhibit insulin signaling pathway in different cells. In C2C12 myotubes, ceramide directly activates protein phosphatase 2A (PP2A), a ubiquitously expressed cytoplasmic serine/threonine phosphatase responsible for dephosphorylation of Akt/PKB [9, 13]. Here, we showed that the defect of insulin stimulate Akt phosphorylation and glucose uptake caused by lipin-1 silencing in C2C12 myotubes could be restored by the pretreatment with okadaic acid, a PP2A inhibitor. Thus, our results suggested that the increased ceramide accumulation might contribute to the insulin resistance induced by lipin- 1 silencing in C2C12 myotubes.

In this study, we also sought to explore the mechanisms of ceramide accumulation in $\mathrm{C} 2 \mathrm{C} 12$ myotubes upon lipin-1 silencing. Intracellular
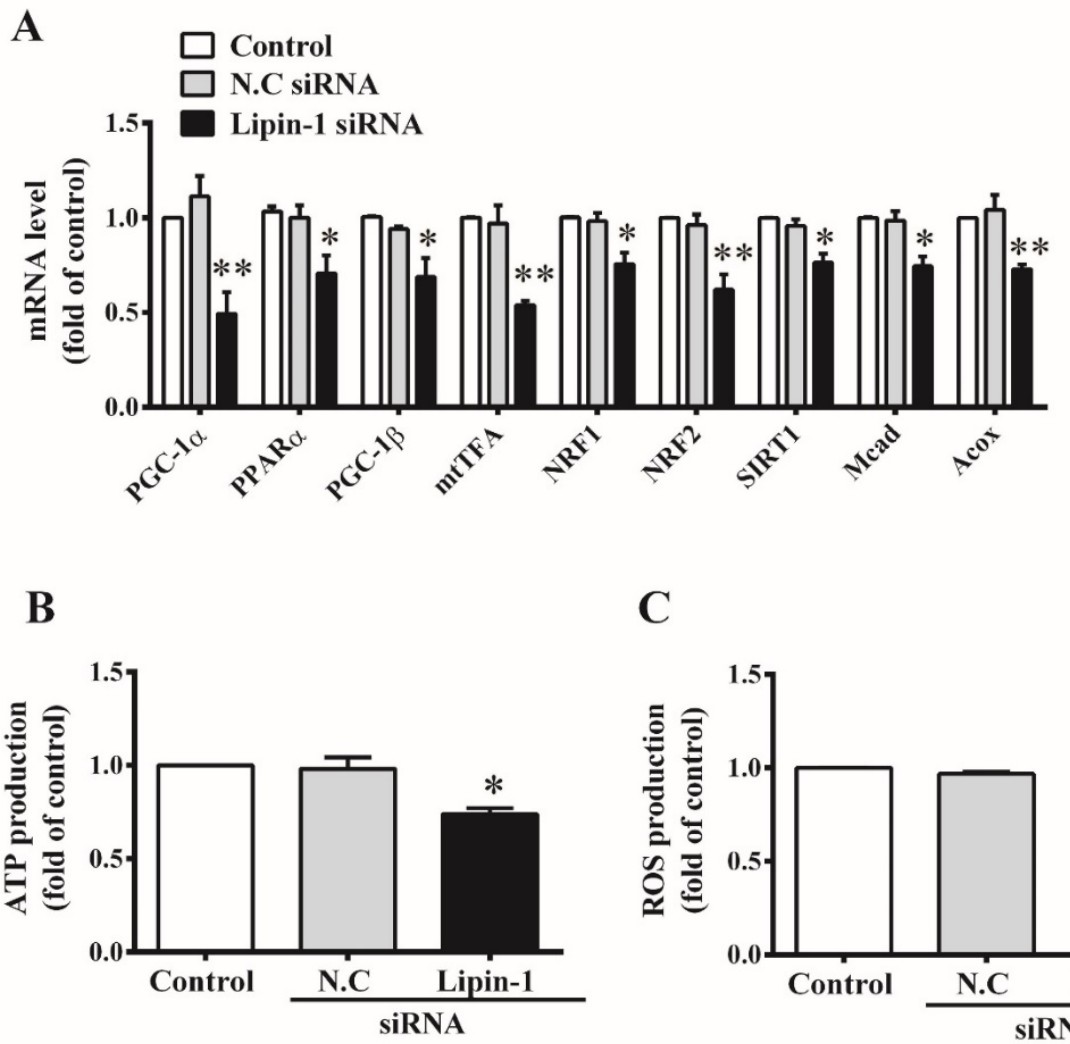

C

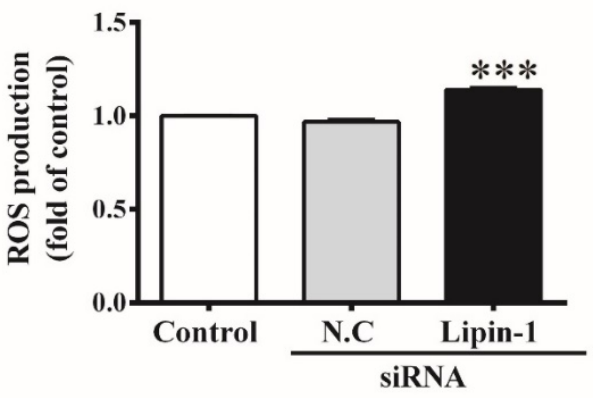

Figure 6. Effect of lipin- 1 silencing on mitochondria function in $\mathbf{C} 2 \mathrm{C} 12$ myotubes. $\mathrm{C} 2 \mathrm{C} 12$ myotubes were transfected with lipin- 1 siRNA for $48 \mathrm{~h}$ following serum starvation for $6 \mathrm{~h}$. Total RNA was extracted and the mRNA levels of genes involved in mitochondrial function were detected by RT-PCR (A). ATP production (B) and intracellular ROS production $(C)$ were also evaluated. Values represent the mean \pm SEM from three or four independent experiments. ${ }^{*} p<0.05$, $* * p<0.01$ and $* * * p<0.001$ vs N.C siRNA. N.C, negative control. 
ceramide accumulation mainly comes from de novo biosynthesis, and the synthesis rate relies on the expression of several enzymes and the availability of the precursors, FAs [36]. We observed no significant changes of the expression of SPT and ceramide synthase mRNA upon lipin-1 silencing in C2C12 myotubes (data not shown). Therefore, the elevation of ceramide levels was speculated to be the result of TAG synthesis and mitochondrial metabolism inhibition. Upon lipin-1 silencing, TAG synthesis was impaired in $\mathrm{C} 2 \mathrm{C} 12$ myotubes, evidenced by decreased levels of TAG and DAG. Moreover, the expression of important genes involved in fatty acid oxidation, such as Mcad and Acox were suppressed and ATP level was decreased, indicated reduced mitochondrial metabolism in lipin-1 silencing C2C12 myotubes. This result might be related with the decreased expression of PGC-1a, which was previously reported as a target gene of lipin-1 in liver. Meanwhile, lipin-1 expression increases after exercise, along with PGC-1a, suggests that lipin-1 may also participate in PGC-1a regulation in skeletal muscle. In this study, mRNA level of PGC-1a was reduced in C2C12 myotubes upon lipin-1 silencing, accompanied with PGC-1a target genes implicated in mitochondrial biogenesis and metabolism. Earlier work demonstrates lipin-1 deficiency in muscle leads to mitochondria dysfunction by suppressing DAG-PKD signaling pathway [31]. Our study further suggested that decreased PGC-1a expression might also participate in the occurrence of mitochondrial dysfunction. Therefore, our results indicated that lipin-1 was a key regulator in controlling FAs flux direction in skeletal muscle, and decreased lipin-1 expression impaired skeletal muscle TAG synthesis and mitochondrial function which led to intracellular ceramide accumulation.

\section{Conclusions}

Lipin-1 is a key lipid metabolism regulator in skeletal muscle. Downregulation of lipin-1 decreased intracellular DAG and TAG levels, but increased ceramide accumulation and thereby caused insulin resistance in $\mathrm{C} 2 \mathrm{C} 12$ myotubes. Our results offer a molecular insight into the role of lipin-1 in the development of insulin resistance in skeletal muscle.

\section{Abbreviations}

DAG: Diacylglycerol; FAs: Fatty acids; FB1: Fumonisin B1; fld: Fatty liver dystrophy; OKA: Okadaic acid; PA: Phosphatidic acid; PAP: Phosphatidate phosphatase; PP2A: Protein phosphatase 2A; SPT: Serine palmitoyltransferase; T2DM: Type 2 diabetes mellitus; TAG: Triacylglycerides.

\section{Acknowledgements}

This work was supported by the National Nature Science Foundation of China (No. 81273565).

\section{Author contribution}

Ying Leng designed research; Shujuan Huang, Suling Huang, Xi Wang, Qingli Zhang and Jia Liu performed research; Shujuan Huang wrote the paper. Ying Leng and Suling Huang reviewed and edited the paper. All the authors gave final approval to the submission of the paper.

\section{Competing Interests}

The authors have declared that no competing interest exists.

\section{References}

1. Sesti G. Pathophysiology of insulin resistance. Best Pract Res Clin Endocrinol Metab. 2006; 20: 665-79.

2. Thiebaud D, Jacot E, DeFronzo RA, Maeder E, Jequier E, Felber JP. The effect of graded doses of insulin on total glucose uptake, glucose oxidation, and glucose storage in man. Diabetes. 1982; 31: 957-63.

3. Ferrannini E, Simonson DC, Katz LD, Reichard G, Jr., Bevilacqua S, Barrett EJ, et al. The disposal of an oral glucose load in patients with non-insulin-dependent diabetes. Metabolism: clinical and experimental. 1988; 37: 79-85.

4. Gulli G, Ferrannini E, Stern M, Haffner S, DeFronzo RA. The metabolic profile of NIDDM is fully established in glucose-tolerant offspring of two Mexican-American NIDDM parents. Diabetes. 1992; 41: 1575-86.

5. Warram JH, Martin BC, Krolewski AS, Soeldner JS, Kahn CR. Slow glucose removal rate and hyperinsulinemia precede the development of type II diabetes in the offspring of diabetic parents. Annals of internal medicine. 1990; 113: 909-15.

6. Nowotny B, Zahiragic L, Krog D, Nowotny PJ, Herder C, Carstensen M, et al. Mechanisms underlying the onset of oral lipid-induced skeletal muscle insulin resistance in humans. Diabetes. 2013; 62: 2240-8.

7. Wright LE, Brandon AE, Hoy AJ, Forsberg GB, Lelliott CJ, Reznick J, et al. Amelioration of lipid-induced insulin resistance in rat skeletal muscle by overexpression of Pgc-1beta involves reductions in long-chain acyl-CoA levels and oxidative stress. Diabetologia. 2011; 54: 1417-26.

8. Mason RR, Mokhtar R, Matzaris M, Selathurai A, Kowalski GM, Mokbel N, et al. PLIN5 deletion remodels intracellular lipid composition and causes insulin resistance in muscle. Mol Metab. 2014; 3: 652-63.

9. Hage Hassan R, Bourron O, Hajduch E. Defect of insulin signal in peripheral tissues: Important role of ceramide. World J Diabetes. 2014; 5: 244-57.

10. Straczkowski M, Kowalska I, Baranowski M, Nikolajuk A, Otziomek E, Zabielski $\mathrm{P}$, et al. Increased skeletal muscle ceramide level in men at risk of developing type 2 diabetes. Diabetologia. 2007; 50: 2366-73.

11. Turinsky J, O'Sullivan DM, Bayly BP. 1,2-Diacylglycerol and ceramide levels in insulin-resistant tissues of the rat in vivo. The Journal of biological chemistry. 1990; 265: 16880-5.

12. Coen PM, Dube JJ, Amati F, Stefanovic-Racic M, Ferrell RE, Toledo FG, et al. Insulin resistance is associated with higher intramyocellular triglycerides in type I but not type II myocytes concomitant with higher ceramide content. Diabetes. 2010; 59: 80-8.

13. Mahfouz R, Khoury R, Blachnio-Zabielska A, Turban S, Loiseau N, Lipina C, et al. Characterising the inhibitory actions of ceramide upon insulin signaling in different skeletal muscle cell models: a mechanistic insight. PLoS One. 2014; 9: e101865.

14. Liu L, Zhang Y, Chen N, Shi X, Tsang B, Yu YH. Upregulation of myocellular DGAT1 augments triglyceride synthesis in skeletal muscle and protects against fat-induced insulin resistance. J Clin Invest. 2007; 117: 1679-89.

15. Jung TW, Hwang HJ, Hong HC, Yoo HJ, Baik SH, Choi KM. BAIBA attenuates insulin resistance and inflammation induced by palmitate or a high fat diet via an AMPK-PPARdelta-dependent pathway in mice. Diabetologia. 2015; 58: 2096-105.

16. Peterfy M, Phan J, Xu P, Reue K. Lipodystrophy in the fld mouse results from mutation of a new gene encoding a nuclear protein, lipin. Nat Genet. 2001; 27: $121-4$.

17. Carman GM, Han GS. Roles of phosphatidate phosphatase enzymes in lipid metabolism. Trends Biochem Sci. 2006; 31: 694-9.

18. Finck BN, Gropler MC, Chen Z, Leone TC, Croce MA, Harris TE, et al. Lipin 1 is an inducible amplifier of the hepatic PGC-1alpha/PPARalpha regulatory pathway. Cell metabolism. 2006; 4: 199-210. 
19. Kim HB, Kumar A, Wang L, Liu GH, Keller SR, Lawrence JC, Jr., et al. Lipin 1 represses NFATc4 transcriptional activity in adipocytes to inhibit secretion of inflammatory factors. Mol Cell Biol. 2010; 30: 3126-39.

20. Reue $\mathrm{K}, \mathrm{Xu} \mathrm{P}$, Wang XP, Slavin BG. Adipose tissue deficiency, glucose intolerance, and increased atherosclerosis result from mutation in the mouse fatty liver dystrophy (fld) gene. J Lipid Res. 2000; 41: 1067-76.

21. Mitra MS, Chen Z, Ren H, Harris TE, Chambers KT, Hall AM, et al. Mice with an adipocyte-specific lipin 1 separation-of-function allele reveal unexpected roles for phosphatidic acid in metabolic regulation. Proc Natl Acad Sci U S A. 2013; 110: 642-7.

22. Csaki LS, Dwyer JR, Li X, Nguyen MH, Dewald J, Brindley DN, et al. Lipin-1 and lipin-3 together determine adiposity in vivo. Mol Metab. 2014; 3: 145-54.

23. Phan J, Reue K. Lipin, a lipodystrophy and obesity gene. Cell metabolism. 2005; 1: 73-83.

24. Gidlund EK, Ydfors M, Appel S, Rundqvist H, Sundberg CJ, Norrbom J. Rapidly elevated levels of PGC-1alpha-b protein in human skeletal muscle after exercise: exploring regulatory factors in a randomized controlled trial. J Appl Physiol (1985). 2015; 119: 374-84.

25. Higashida K, Higuchi M, Terada S. Potential role of lipin-1 in exercise-induced mitochondrial biogenesis. Biochemical and biophysical research communications. 2008; 374: 587-91.

26. Karaskov E, Scott C, Zhang L, Teodoro T, Ravazzola M, Volchuk A. Chronic palmitate but not oleate exposure induces endoplasmic reticulum stress, which may contribute to INS-1 pancreatic beta-cell apoptosis. Endocrinology. 2006; 147: 3398-407.

27. Huang SL, Yu RT, Gong J, Feng Y, Dai YL, Hu F, et al. Arctigenin, a natural compound, activates AMP-activated protein kinase via inhibition of mitochondria complex I and ameliorates metabolic disorders in ob/ob mice. Diabetologia. 2012; 55: 1469-81.

28. Obanda DN, Hernandez A, Ribnicky D, Yu Y, Zhang XH, Wang ZQ, et al. Bioactives of Artemisia dracunculus L. mitigate the role of ceramides in attenuating insulin signaling in rat skeletal muscle cells. Diabetes. 2012; 61: 597-605.

29. Deng $\mathrm{P}$, Zhong D, Wang X, Dai Y, Zhou L, Leng Y, et al. Analysis of diacylglycerols by ultra performance liquid chromatography-quadrupole time-of-flight mass spectrometry: Double bond location and isomers separation. Anal Chim Acta. 2016; 925: 23-33.

30. Martins AR, Nachbar RT, Gorjao R, Vinolo MA, Festuccia WT, Lambertucci $\mathrm{RH}$, et al. Mechanisms underlying skeletal muscle insulin resistance induced by fatty acids: importance of the mitochondrial function. Lipids Health Dis. 2012; 11: 30.

31. Zhang P, Verity MA, Reue K. Lipin-1 regulates autophagy clearance and intersects with statin drug effects in skeletal muscle. Cell metabolism. 2014; 20 : 267-79.

32. Dwyer JR, Donkor J, Zhang P, Csaki LS, Vergnes L, Lee JM, et al. Mouse lipin-1 and lipin-2 cooperate to maintain glycerolipid homeostasis in liver and aging cerebellum. Proc Natl Acad Sci U S A. 2012; 109: E2486-95.

33. Jiang W, Zhu J, Zhuang $X$, Zhang $X$, Luo T, Esser KA, et al Lipin1 Regulates Skeletal Muscle Differentiation through Extracellular Signal-regulated Kinase (ERK) Activation and Cyclin D Complex-regulated Cell Cycle Withdrawal. The Journal of biological chemistry. 2015; 290: 23646-55.

34. Schmitz-Peiffer C, Craig DL, Biden TJ. Ceramide generation is sufficient to account for the inhibition of the insulin-stimulated PKB pathway in $\mathrm{C} 2 \mathrm{C} 12$ skeletal muscle cells pretreated with palmitate. The Journal of biological chemistry. 1999; 274: 24202-10.

35. Abdul-Ghani MA, DeFronzo RA. Pathogenesis of insulin resistance in skeletal muscle. J Biomed Biotechnol. 2010; 2010: 476279.

36. Bosma M, Kersten S, Hesselink MK, Schrauwen P. Re-evaluating lipotoxic triggers in skeletal muscle: relating intramyocellular lipid metabolism to insulin sensitivity. Prog Lipid Res. 2012; 51: 36-49.

37. Holland WL, Brozinick JT, Wang LP, Hawkins ED, Sargent KM, Liu Y, et al. Inhibition of ceramide synthesis ameliorates glucocorticoid-, saturated-fat-, and obesity-induced insulin resistance. Cell metabolism. 2007; 5: 167-79.

38. Kurek K, Miklosz A, Lukaszuk B, Chabowski A, Gorski J, Zendzian-Piotrowska M. Inhibition of Ceramide De Novo Synthesis Ameliorates Diet Induced Skeletal Muscles Insulin Resistance. J Diabetes Res. 2015; 2015: 154762.

39. Ussher JR, Koves TR, Cadete VJ, Zhang L, Jaswal JS, Swyrd SJ, et al. Inhibition of de novo ceramide synthesis reverses diet-induced insulin resistance and enhances whole-body oxygen consumption. Diabetes. 2010; 59: 2453-64. 